\section{References}

${ }^{1}$ Remuzzi, G, et al, British Medical fournal, 1977, 2, 359.

2 Salzman, E W, and Neri, L L, Thrombosis et Diathesis Haemorrhagica, 1966, 15, 84.

${ }^{3}$ Horowitz, H I, Archives of Internal Medicine, 1970, 126, 823.

4 Rabiner, S F, Medical Clinics of North America, 1972, 56, 221.

5 Lindsay, R M, et al, Clinical Nephrology, 1976, 6, 335.

6 Kazatchkine, M, et al, British Medical fournal, 1976, 2, 612.

7 Ruggeri, Z M, Ponticelli, C, and Mannucci, P M, British Medical fournal, $1977,1,1085$.

${ }^{8}$ Herrmann, R P, Marshall, L R, and Hurst, P E, British Medical fournal, $1977,1,1601$.

${ }^{9}$ Bloom, A L, Giddings, J C, and Wilks, C J, Nature New Biology, 1973, 241, 217.
10 Jaffe, E A, Hoyer, L W, and Nachman, R L, fournal of Clinical Investigation, 1973, 52, 2757.

1 Jaffe, E A, Hoyer, L W, and Nachman, R L, Proceedings of the National Academy of Sciences of the United States of America, 1974, 71, 1906.

12 Jaffe, E A, and Nachman, R L, fournal of Clinical Investigation, 1975, 56, 698.

13 Caen, J P, and Sultan, Y, Lancet, 1975, 2, 1129

$14 \mathrm{Jaffe}, \mathrm{E}$ A, New England fournal of Medicine, 1977, 296, 377.

15 Holmberg, L, et al, Scandinavian Fournal of Haematology, 1974, 13, 33.

16 Praga, C, Cortellaro, M, and Pogliani, E, in Platelet Function and Thrombosis. A Review of Methods, ed P M Mannucci and S Gorini, p 149. New York, Plenum Press, 1972.

\title{
Birth ranks of spontaneous abortions in sibships of children affected by anencephaly or spina bifida
}

\author{
WILLIAM H JAMES
}

British Medical fournal, 1978, 1, 72-73

\section{Summary and conclusions}

Data on the birth rank of miscarriages within sibships in which a case of anencephaly or spina bifida (ASB) had occurred were analysed by the Haldane-Smith statistical test. This showed that miscarriages in ASB sibships tend to have a negative birth order effectthat is, they occur in earlier rather than later pregnancies within the sibship. The strongest source of bias in this analysis-the fact that mothers tend to forget early spontaneous abortions-worked against this finding, so the negative birth order effect is probably genuine.

Because ASB itself shows a negative birth order effect and because spontaneous abortions in normal sibships do not show such an effect, the additional spontaneous abortions in ASB sibships are probably of fetuses affected by ASB.

\section{Introduction}

There is a high incidence of spontaneous abortion among pregnancies in sibships in which a case of anencephaly or spina bifida (ASB) has occurred. ${ }^{1}$ - Also, relatively few pregnancies in which the fetus is affected by ASB reach full term: many more are either terminated or spontaneously aborted. ${ }^{3}{ }^{4}$ It seems natural to suppose that the additional spontaneous abortions in ASB sibships occur among fetuses that also have ASB.

This interpretation has now been questioned in one of the elaborations of the fetus-fetus interaction hypothesis. ${ }^{5-7}$ Instead it has been suggested that ASB is somehow caused by a previous spontaneous abortion. This suggestion was supported by the observation, ${ }^{7}$ now confirmed by Laurence and Roberts, ${ }^{8}$ that the pregnancy immediately before the index pregnancy, which resulted in a child with ASB, is more likely to have been reported to have miscarried than the pregnancy immediately after it. In discussing this point, Clarke et $a l^{7}$ raise the possibility

that miscarriages occur early rather than late in families. They dismiss this explanation, however: "The data gave no evidence for such a view, and in one series (anencephaly in Appendix 1 of Carter et $a l^{9}$ ) miscarriages came on average significantly later." In this paper I want to reconsider this point.

It is true that the percentage of pregnancies reported as miscarrying increased from $7^{\circ}{ }_{0}$ in the first to $20^{\circ}{ }_{0}$ in the fourth birth rank in the data of Carter et al. But the question is not whether the proportion of pregnancies miscarrying increases from rank to rank, but whether within sibships the probability of having a miscarriage increases from rank to rank. These two questions are not the same; indeed, it would be possible for the incidence of spontaneous abortion to rise with birth rank even if the probability of a spontaneous abortion declined within individual sibships. (This might arise if spontaneous abortions were commoner in large than in small sibships.)

\section{Statistical analysis}

To test whether the liability to miscarriage varies from one birth rank to another within sibships I used the test of Haldane and Smith. ${ }^{10}$ This test assumes a null hypothesis that the birth ranks of the affected siblings are equiprobable. The actual sum of the affected birth ranks is compared with the sum that would have been obtained if the null hypothesis had been true. The difference between the two sums divided by an estimate of the standard error is approximately normally distributed and provides an estimate of the probability that the actual sum would have been observed if the null hypothesis had been true.

I analysed all the sibships reported by Carter $e t a l^{9}$ and by Williamson $^{11}$ in which cases of ASB had occurred. The birth ranks of pregnancies that ended in miscarriages were tested against those of all the other pregnancies (affected and unaffected) in each sibship. Multiple births were counted as occupying one birth rank. Miscarriages had occurred in 210 sibships, and for these data the test statistic of ¿6A took the value of 4812 with an expected value of 5175 and a sampling variance of 19311 . This gave a $\mathrm{z}$ score of $2.6(\mathbf{P}<0.01)$. These data therefore strongly suggested that miscarriages in ASB sibships tended to occur among the earlier rather than the later pregnancies.

\section{Sources of bias}

Studies on birth order effects are notoriously susceptible to bias so it is worth considering some of the sources of bias.

Memory-Rates of reported spontaneous abortion may be categor- 
ised simultaneously by the age of the mother at occurrence and by her age at interview. ${ }^{12}{ }^{13}$ For a given age of occurrence the reported spontaneous abortion rate varies inversely and substantially with the interval since the occurrence. Such an effect is absent from data on reported stillbirth rates. ${ }^{14}$ This suggests that (presumably because of memory deficit) women are less likely to report spontaneous abortions occurring early in their histories than those occurring more recently. So the finding of Clarke et al and of Laurence and Roberts occurred in spite of this phenomenon and not because of it.

Incompleteness of sibships-It is not clear that this feature of the data has seriously biased the birth ranks of the miscarriages.

Compensation-There is good evidence that parents compensate after a miscarriage by starting another pregnancy. ${ }^{15} 16$ In such circumstances a Haldane-Smith test would yield a slight spurious suggestion of a negative birth order effect in the absence of a true one. ${ }^{17}$ It seems unlikely, however, that such a tendency could have affected the present results appreciably, if only because the sibships were incomplete.

The strongest bias (memory) was therefore working in the opposite direction to the present result. This suggests that the effect detected here is genuine and not a statistical artefact.

\section{Discussion}

The results seem to confirm speculation ${ }^{18}$ that miscarriages in ASB sibships show a negative birth order effect-that is, they are more likely to occur among the early than among the late birth ranks. This is in contrast to the position in random sibships, where there does not seem to be an overall negative birth order effect in spontaneous abortions. ${ }^{818}$ But ASB itself also shows a negative birth order (or at least primiparity) ${ }^{19-21}$ effect, which seems even more pronounced when some attempt is made to control variation due to social class. ${ }^{22}$ Taken together these facts seem to suggest that the additional spontaneous abortions in ASB sibships are not "normal" spontaneous abortions but further cases of ASB. Otherwise the question arises: Why do cases of ASB have a negative birth order effect when their putative cause-miscarriages of fetuses without ASB-do not?

I am supported by the National Fund for Research into Crippling Diseases.

References

1 Coffey, V P, and Jessop, W J E, Irish Fournal of Medical Science, 1958, 393, 391.

2 Book, J A, and Rayner, S, American fournal of Human Genetics, 1950, 2, 61 .

${ }^{3}$ Creasy, M R, and Alberman, E D, fournal of Medical Genetics, 1976, 13, 9.

${ }^{4}$ Nishimura, $\mathrm{H}$, in Proceedings of the Third International Conference on Congenital Malformations, ed F C Fraser and V McKusick. Amsterdam, Excerpta Medica, 1970.

${ }^{5}$ Knox, E G, Developmental Medicine and Child Neurology, 1970, 12, 167

6 Knox, E G, British fournal of Preventive and Social Medicine, 1974, 28 , 73.

7 'Clarke, C, et al, British Medical fournal, 1975, 4, 743.

${ }^{8}$ Laurence, K M, and Roberts, C J, British Medical fournal, 1977, 2, 361.

${ }^{9}$ Carter, C O, David, P A, and Laurence, K M, fournal of Medical Genetics, $1968,5,81$.

${ }^{10}$ Haldane, J B S, and Smith, C A B, Annals of Eugenics, 1947, 14, 117.

${ }^{11}$ Williamson, E M, fournal of Medical Genetics, 1965, 2, 161.

12 Jain, A K, Milbank Memorial Fund Quarterly, 1969, 47, 297.

${ }^{13}$ Léridon, H, Population Studies, 1976, 30, 319.

${ }^{14}$ Yerushalmy, J, et al, American fournal of Obstetrics and Gynecology, 1956, 71, 80.

${ }^{15}$ James, W H, American fournal of Human Genetics, 1963, 15, 223.

16 James, W H, Population Studies. In press.

17 James, W H, Applied Statistics, 1969, 18, 276.

18 James, W H, fournal of Biosocial Science, 1974, 6, 23.

${ }^{19}$ Edwards, J H, British fournal of Preventive and Social Medicine, 1958, 12 115 .

${ }^{20}$ McKeown, T, in First International Conference on Congenital Malformations, ed M Fishbein. Philadelphia, Lippincott, 1961.

${ }^{21}$ Czeizel, A, and Revesz, C, British fournal of Preventive and Social Medicine, 1970, 24, 205.

22 James, W H, Annals of Human Genetics, 32, 223, 1969.

\title{
Adrenocortical suppression in workers manufacturing synthetic glucocorticoids
}

\author{
R W NEWTON， MARGARET C K BROWNING，J IQBAL， N PIERCY， D G ADAMSON
}

British Medical fournal, 1978, 1, 73-74

\section{Summary and conclusions}

A man who had worked for 16 years in the manufacture of a potent corticosteroid was found to be suffering from chronic adrenocortical insufficiency attributed to chronic absorption of the glucocorticoid. Eleven other symptomfree workers were therefore screened. Two of these workers, like the first patient, gave grossly abnormal responses to the Synacthen (tetracosactrin) test; one had been employed for only seven months.

Ninewells Hospital and Medical School, Dundee

$R$ W NEWTON, MRCP(UK), senior registrar in medicine and endocrinology; now consultant physician

MARGARET C $\mathrm{K}$ BROWNING, BSC, biochemist

J IQBAL, MB, senior house officer

N PIERCY, MRCGP, general practitioner

D G ADAMSON, FRCP, consultant physician
All 12 men had facial plethora, suggesting absorption of the drug in spite of their having adhered to the safety precautions. All workers manufacturing potent steroids should therefore be screened regularly by measurement of their plasma cortisol concentrations and should be moved regularly to processing other drugs.

\section{Introduction}

Many studies have demonstrated adrenocortical suppression in patients receiving long-term steroid treatment for a variety of diseases ${ }^{1-5}$; but such suppression has not previously been demonstrated in workers manufacturing synthetic glucocorticoid drugs. Our study was prompted by investigations on a man who had worked for 16 years at various stages of production of a potent corticosteroid.

\section{Case report}

Case 1-Although symptom-free while working, this man complained for two years of general ill health during periods of absence 